\title{
Electronic Field Guides and User Communities in the Eco- informatics Revolution
}

\author{
$\underline{\text { R. D. Stevenson }}^{1}, \underline{\text { William A. Haber }}^{2}$, and $\underline{\text { Robert A. Morris }}^{1}$
}

\begin{abstract}
The recognition that taxonomy is central to the conservation of biodiversity has reestablished the critical role of taxonomy in biology. However, many of the tools taxonomists produce for the identification and characterization of species, e.g., dichotomous keys, have been difficult to use and largely ignored by the general public in favor of field guides, which are essentially browsable picture guides. We review the role of field guides in species identification and discuss the application of a host of digital technologies to produce user-friendly tools for identification that are likely to greatly enhance species identification in the field by nonspecialists. We suggest that wider adoption of the citizen science model and the use of electronic field guides will enhance public understanding and participation in biodiversity monitoring.
\end{abstract}

\section{INTRODUCTION}

What would Florence Merriam Bailey and Roger Tory Peterson have invented if they had grown up with Personal Digital Assistants (PDAs) and the Internet?

During the last $20 \mathrm{yr}$, attention to the loss of our biological heritage and resources has moved from a largely academic concern to a mainstream policy issue at all levels of society. The term "biodiversity" came into widespread use in the late 1980s (Wilson 1988, Reid and Miller 1989, McAllister 1997, Read 1997) and, along with the term "nature's services" (Daily 1997, Balmford et al. 2002), has come to symbolize these concerns. Activities by scientists, nongovernmental organizations, educators, and governments directed at the biodiversity crisis continue to expand in scope. (For recent examples, see Ricketts et al. 1999 or Stein et al. 2000, or sample some of the many Internet sites beginning at http://www.sciencemag.org/feature/data/biodiversity2 000.shl, http://www.geocities.com/RainForest/Vines/8695/, or www.biodiversity.uno.edu/). The sponsorship of the Global Biodiversity Information Facility by the Organisation for Economic Co-Operation and Development testifies to the understanding that biodiversity conservation is a critical issue of global significance.

At the core of biodiversity conservation efforts are the discovery and maintenance of knowledge about species and their distributions. For the last $250 \mathrm{yr}$, since Linnaeus (Knapp 2000), this task has been the purview of the taxonomists who work in collections where specimens are housed. Unfortunately, knowledge of biodiversity is limited. Certainly, fewer than $20 \%$ of the estimated species have received scientific names, and human and physical infrastructures for recording, cataloging, and identifying species are currently insufficient for the task (Raven and Wilson 1992, Janzen et al. 1993, Blackmore 1996, Wilson 2000). In addition, what knowledge we have is often difficult to access because it is available only in very specialized technical publications of limited distribution or recorded on file cards and specimen labels in museums. However, efforts to change this situation are increasing (Day 1998, President's Council of Advisors on Science and Technology 1998, GBIF 2001), especially with regard to sharing information over the Internet (Bisby 2000, Edwards et al. 2000, Pennisi 2000).

Central to these efforts is the use of scientific names for species. This formal designation allows the scientific community to communicate about individuals that occur in nature in a standardized fashion. For more than $100 \mathrm{yr}$, the taxonomic community has recognized the necessity of naming standards and three slightly different but wellestablished International Codes of Nomenclature exist for zoology, botany, and bacteria, respectively. 
Furthermore, the Taxonomic Database Working Group (TDWG) and Integrated Taxonomic Information System (ITIS) are working to establish electronic interchange standards. (See Species 2000 standards and those of the Global Biodiversity Information Facility). The recent paper by Ytow et al. (2001) summarizes the taxonomic issues well and provides a new information model.

It may be as important to adopt standards for common names as it is for scientific names when it comes to the preservation of biodiversity (P. Alden, personal communication). For a few taxa, such as birds and butterflies, there are committees that provide widely accepted standards for common names (e.g., American Ornithologists' Union 2000, Cassie et al. 2001, and the suggestions of the Ecological Society of America). For other taxa, especially plants, common names can generate great confusion; to see this in action, try searching "loosestrife," "loose-strife," and "loose strife" in Google and in the U.S. Department of Agriculture plants database. Having a process and standard rules for forming common names would be a great help for both the professional and the amateur user communities in finding information (Parkes 1978, Kartesz and Thieret 1991).

Once standards have been accepted in a discipline, the community can usually move on to other business (Rumble 1999). In taxonomy, however, names change. Species are lumped or split depending on the information available or the judgment of the authority involved. Changing names are a reflection of the infancy of the discipline and the fact that judgments are made without complete information. Although this flexibility is absolutely necessary, it detracts from the notion of a standard and makes it more difficult for people, especially nonspecialists, to communicate.

In addition to naming species, taxonomists provide keys for identifying species. The traditional approach, following Linnaeus, has been to construct dichotomous keys. However, these keys are notoriously difficult to use (ask nontaxonomists or beginning biology students), so an entirely different approach was developed for the public: the field guide. In fact, a small group of people, mostly naturalists rather than scientists, write and illustrate field guides (National Audubon, Golden, Peterson, and Stokes series) that translate taxonomic information into a form that the public can use.

These communication difficulties, combined with the fact that most biologists work on a few model species, led to the perception that taxonomy was an inwardlooking and arbitrary science, not a place to make a career. As a result, the biological community marginalized taxonomy, and the taxonomic community has been poorly funded (Godfray 2002). Now, as taxonomy moves into the bioinformatics age, the image of people relegated to dusty basements in monolithic museum buildings is being replaced by digital technologies including bar code labeling, imaging equipment, GIS equipment, and Internet databases (Gewin 2002). In keeping with their new outlook, taxonomic professionals are making a greater effort to share their expertise and information. Now that the indispensable role of taxonomy for biodiversity studies has been acknowledged, taxonomists are rebuilding their support and regaining their status in the biological community. Here we consider how taxonomic information can be more widely shared using electronic media and the field guide approach. We discuss the communities, mainly applied and recreational groups, that "consume" taxonomic information. We review the history of field guides and their impact, describe their essential elements and variety, and ask what kinds of field guides and elements of field guides are already being published electronically. We discuss the problems associated with helping people to identify an organism with the correct scientific name. We argue that a more scientific approach to developing keys and guides should be adopted. Finally, we consider the "citizen science" paradigm and the implications that being able to label specimens with their correct scientific names would have for preserving biodiversity and monitoring the environment.

\section{CONSUMERS OF TAXONOMIC INFORMATION}

Who are the consumers of information about species? Who needs to have access to scientific names? Pankhurst (1991, Chapter 7) provides a list that focuses on the professional disciplines. For the most part, the consumers of this information are not the mainstream biologists working at lab benches solving problems in medical science, but rather a diverse set of people who might be called "applied and recreational field biologists and naturalists." These include professionals in the areas of public health, agriculture, and land management; educators at schools and nature camps; and recreational users such as birders, gardeners, mushroom hunters, and ecotourists. Often their needs are very specific. They need help identifying species, and a field guide, with direct 
coaching from specialists, is often the method they use.

\section{FIELD GUIDES}

\section{History of field guides}

We can review the history of field guides in general by studying the history of field guides to birds. Florence Merriam Bailey, sister of C. Hart Merriam, the first chief of the U.S. Biological Survey (1885-1910) and wife of the well-known zoologist Vernon Bailey, is credited with writing the first field guide in 1889 . Titled Birds Through an Opera Glass, this book contains wonderful descriptions but only a few black and white illustrations. Others readily adopted the noncollecting approach. For instance, in the fifth edition of Our Common Birds and How to Know Them, which was first published in 1891, Grant (1895:14) writes, "But if the would-be observer looks forward to what may be called professional work, and intends to make an exhaustive study of ornithology, he must kill birds and learn to skin and preserve them ... In the present little work this branch of the subject will not be discussed, and only such familiarity with birds will be sought for as may be attained by direct observation alone and through the instrumentality of no weapon more deadly than the opera glass."

In 1898, Bailey completed Birds of Village and Field: a Bird Book for Beginners, and later in 1902 came the Handbook of Birds of the Western United States. The handbook included information about the dimensions of birds, was arranged by taxonomic order, and gave clear descriptions of each species, its distribution, food, and nest. Thus, it contained many of the elements of a modern field guide. As a leading advocate for the protection of birds and a founding member of the Audubon Society, it is not surprising that Florence Bailey was an early advocate of using binoculars and field guides, rather than collecting birds with guns, to identify them. (For more information on Florence Bailey, see http://www.northnet.org/stlawrenceaauw/bailey.htm)

After Bailey, Chester Reed, among others, published books that are clear forerunners of the modern field guide. These efforts were part of the new conservation movement, popular ornithology, that blossomed in America between 1850 and1920. For additional resources in this area, see the Library of Congress.

The modern breakthrough came in the 1930s, when
Professor Ludlow Griscom showed that it was possible to identify birds reliably without killing them (Hill 1965). Based on his experiences with Griscom, the tradition initiated by Florence Bailey, and his wonderful skill as an artist, R. T. Peterson (1934) then developed the first modern field guide, A Field Guide to the Birds. Essential to his system were color plates with paintings of similar species in which Peterson indicated field marks. People could easily compare the species they saw in the field with these paintings and make an identification (Leahy 1982). This guide proved to be an essential tool that enabled casual bird observers to become skilled "birders." Commenting on the impact of Peterson's guide, Youth (1998) writes "Wildlife watching, especially birding, has become one of the nation's most popular pastimes, the offshoot of a vast increase in environmental awareness since the hawk-shooting days before 1934, when Hawk Mountain was transformed from shooting gallery to wildlife sanctuary. Field guides allowed the development of a large group of skilled amateur birders, which has had an enormous impact. Birding is a sport, an industry, and an educational tool. Birding encourages people to reconnect with nature and therefore to value it. Birders are the backbone of the environmental movement as evidenced by the well-established Audubon Societies and Rachel Carson's metaphor "silent spring." Birders are growing in number, and birding may soon surpass hunting and fishing in popularity (Cordell et al. 1998, Cordell et al. 1999).

\section{Components of modern field guides}

Although there is no strict definition of what constitutes a field guide, normally it is specific to a particular taxon or life form and covers a limited geographic area that can be defined by political or biogeographic boundaries. Common features include a book format that is divided into two sections. The first introduces the group and often subgroups within the taxon being presented, with a description of taxonomy, basic biology, morphology, and observation and collection techniques, followed by a definition of what is to be found in each of the species accounts. Often, simple keys that can be used in the field are provided; typically, these are wider than classical dichotomous keys.

The second, and larger, section contains species accounts with graphic and written materials. The accounts are organized taxonomically, or by some critical morphological character such as flower color in the case of wildflowers. A central feature is a collection of photographs, drawings, or paintings of 
each species, which are labeled with a name. These present the species in lifelike postures and may include arrows to indicate field marks. The pictures allow the user to compare similar-looking species side by side. When variation within a species exists, such as between the sexes or between adult and juvenile forms, that too may be illustrated. In fact, the illustrations can account for more than $50 \%$ of all the printed material in the species account section. In some designs, the illustrations are presented as a series of color plates, and naturalists have been known to remove the plates and have them rebound for field use so as to minimize volume and weight. For the new "pocket" guides, i.e., small laminated foldouts or cards, all the user gets is a picture with a name.

The written portion of an account typically contains information on names, taxonomy, identification tips, habitats, behavior, life stages, ecology, range maps with data about seasonal movements, relationships to humans, and conservation. Content and format vary widely with the taxon, the age and experience of the audience, and the geographic coverage of the guide. For birding, field-guide niche markets exist for beginner, standard, and advanced levels.

\section{Identification using field guides}

How is this information used to identify species? The identification process relies on a combination of simple keys as the user scans the illustrations for a match and carefully compares what is known about the specimen in view or in hand with pertinent text and graphical information provided in the guide. The keys help people focus their search in a section of the book in which the number of choices is relatively small. Usually it is possible to scan the species illustrations adjacent to the tentative identification. Bird and butterfly guides often have little in the way of keys, whereas plant guides are much more likely to use two or three different characteristics to help users narrow their scanning efforts.

Particularly useful are guides that give references to similar species in each species account. Users can make direct comparisons with these to increase the confidence of a positive identification. Sometimes, one single taxon-specific character among all of those given is enough to identify the species. For a tree this might be a leaf, a flower, a twig, a fruit, or a piece of bark. For a bird it might be a silhouette, a feather, a song, or a movement pattern along a branch.
Fig. 1. The fraction of field guides in six categories for the entire USA (data from Amazon.com) and for the Pacific Northwest (data from

http://www.tardigrade.org/natives/fieldguides.htm). Birdrelated guides accounted for more than $70 \%$ of those available for the entire United States at Amazon.com, whereas plant-related guides represented more than $55 \%$ of the sales of a natural history source located in the Pacific Northwest. These differences may reflect public interest, commercial decisions, or seller biases.

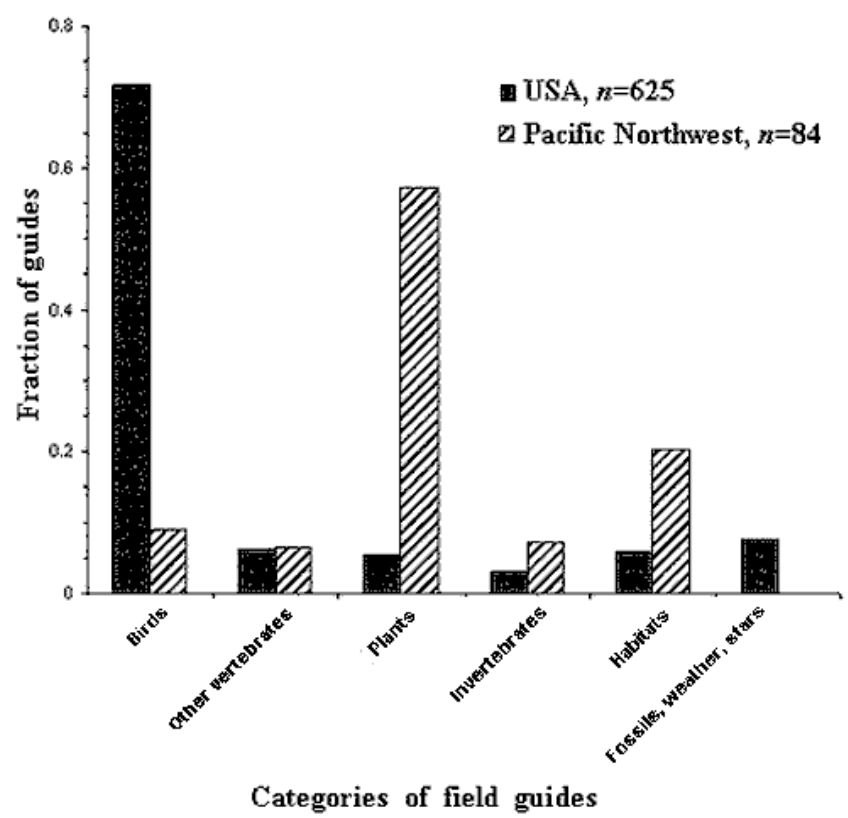

\section{Limitations to commercially available field guides}

The economics of traditional publishing dictate that paper field guides must have commercial viability, so they tend to focus on popular taxa, cover wide geographic areas, and contain many species. A review of titles from the major series of U.S. field guides (Audubon, Golden Guides, Peterson, Stokes) reveals more than 20 common topics for field guides, including animal tracks, birds, butterflies, edible wild plants, fishes, fossils, insects, medicinal plants, mushrooms, plants, pond life, reptiles and amphibians, rocks and minerals, seashells, seashores, stars, trees, weather, weeds, wildflowers, and venomous animals and plants. A search of Amazon.com in December 2000 using "field guide" as a key phrase found 625 natural history guides, of which more than $70 \%$ were about birds (Fig. 1). Twelve months later, this total had more than tripled, but we did not attempt to 
analyze the results or filter them for duplicates. The topic is so popular that Amazon's subject navigation can now lead the searcher through "Natural History" to "Field Guides" to discover 2019 entries.

The variety of specialized bird guides now available leaves the impression that bird guides exist for every corner of the world and that birding has become big business. The other five categories (nonbird vertebrates, plants and mushrooms, invertebrates, habitats, and fossils, weather, and stars) each represented $3-8 \%$ of the total. Constraints on size and cost usually preclude showing regional, seasonal, and developmental variations in a guide covering many species. If the guides are produced for a regional area, the quality of the illustrations is usually not as good, to keep the price down for the smaller market. A recent exception is Sibley's (2000) new bird guide, which has many illustrations but is priced on a par with other guides.

There is a plethora of modern field guides in print, but, aside from the standard categories listed above from major publishers, they may be difficult to find. For instance, a list of field guides for the Pacific Northwest contains 84 references and has a very different taxonomic emphasis from those on the Amazon list (Fig. 1). More than 55\% are about plants (trees, wildflowers) and mushrooms (poisonous, edible), 20\% about habitats, and slightly less than $10 \%$ about birds. Many of these books are from smaller publishers with regional coverage. Note that we did not make any direct comparisons between this set and the Amazon set in terms of the number of species, costs, and quality of illustrations.

A second example concerns amphibians and reptiles. In 2000, a search of Amazon.com turned up only 10 guides to amphibians and reptiles, but Livo (1998) lists 147 publications, including field guides, checklists, and handbooks, many of which are from academic presses. A similar search one year later produced 83 titles, many from small publishers. Clearly, more complete information is available in less popular and less commercially viable forms, and large online booksellers may now be able to address more specialized audiences. At the Internet site of the Colorado Herpetological Society, Arlen (1999) reviews recordings of frog calls. Commercial book and music stores, whether traditional or e-stores, do not yet have such complete lists.

\section{Electronic field guides}

\section{CD-ROMs}

As with paper field guides, most electronic products deal with birds. Commercial birding software (Table 1) includes more than $10 \mathrm{CDs}$ with all the features for identifying birds found in paper guides, except that as yet they cannot be easily used in the field. The usual advantages of electronic documents are apparent in these products: hypertext links, more color photographs, and greater amounts of information, such as the inclusion of both field marks and songs for identifying species. Programs may allow users to search on shape, size, color, habitat, or unique behaviors. The games and quizzes featured in some software products help users learn the birds. More than half a dozen programs exist that allow birders to keep track of the birds they see (Table 1). These "listing" programs include a variety of options for the output of information such as life lists and maps of records. Some of these products are reviewed by the New Jersey Audubon Society and Biosis Taxonomy and Nomenclature Software.

Examples of electronic guides exist for other taxa such as plants and butterflies (e.g., ETI's collection). Sometimes these CDs are technically oriented and not intended for the general public. There is a host of highquality programs available commercially or for free that were conceived mainly for the storage and use of biodiversity information in more scientific settings. These include Biolink, Biota, Delta, Linnaeus II, and Lucid, which run in a variety of operating environments and platforms. For details, see the Internet Directory for Botany: Software and the Internet Resource Guide for Zoology.

A growing number of Internet sites offer some information about species, but by far the largest and most complete is eNature. At this writing, it has 13 categories of field guides from the Audubon series online, and claims entries covering more than 5000 species. Users can search for species by name, browse by thumbnail photos, or use an advanced search tool that categorizes species by color, size, habitat, and geographic region. For well-known vertebrate species, it is possible to search a list of common species or a list that contains all species. The site also offers the ability to search within bioregion areas of states. For less well-known taxa, such as dragonflies, information is provided only for common species. For information about Lepidoptera, the Internetguide to North 
American butterflies by Opler, Stanford, and Paluvann or to moths by Opler might be better places to look than eNature. eNature's additional features include the option to keep track of an observer's sightings, to have questions answered by an expert, and to get regular natural history notes by e-mail.

Many fine noncommercial sites for avian species offer the same features as paper field guides, such as species accounts with maps (Table 1). We also found a heterogeneous collection of more than 60 electronic field guides unrelated to bird guides (Appendix 1). Some are large sites, such as FishBase, which contains all the world's fish species, or Species Identification: an Online Guide for Amphibians in the United States and Canada, but most are small with a very specific focus. The guides listed in Appendix 1 cover North
American mushroom species, schoolyards, economically important seaweeds in New England, anemones and the fishes they host, intestinal microsporidiosis, and the diagnosis and management of potato late blight. They illustrate the diversity of the applied fields that have published electronic guides.

One of most innovative approaches to electronic guides on the Internet lets users build their own field guides (Royal Ontario Museum 1999). The software uses a three-step process in which the user picks from one of 54 areas in Ontario, Canada; selects one of three groups (birds, amphibians, or fish); and chooses either a field guide or a checklist output format. This ability to construct guides to match user needs is one of the most significant advantages of electronic document processing.

Table 1. Categories of birding software with examples and/or descriptions and/or Internet addresses.

\begin{tabular}{|c|c|c|}
\hline Software category & Example & Description/Internet address \\
\hline \multirow[t]{11}{*}{ Interactive field guides } & Natureware & $\begin{array}{l}\text { CD-ROM with more than } 2400 \text { illustrations of almost } 700 \\
\text { birds in Eastern USA }\end{array}$ \\
\hline & Birds of Europe & CD-ROM from Springer-Verlag \\
\hline & Birder's Mate & Field guide for notebooks and PCs, South Africa \\
\hline & Birds of the World & CD-ROM encyclopedia covering 768 birds in 80 species \\
\hline & $\begin{array}{l}\text { North American Bird } \\
\text { Reference Book }\end{array}$ & $\begin{array}{l}\text { Instructional multimedia CD-ROM, with songs, photos, } \\
\text { quizzes, maps, and more. For PCs. }\end{array}$ \\
\hline & $\begin{array}{l}\text { Birds of North America } \\
\text { CD-ROM } 2.5\end{array}$ & $\begin{array}{l}\text { From Thayer's: songs, photos, videos, quizzes, field guide, } \\
\text { and more. For PC's. }\end{array}$ \\
\hline & Birds of the World & Covers 9946 birds of the world. For PCs. \\
\hline & $\begin{array}{l}\text { Multimedia Birds of } \\
\text { Southern Africa }\end{array}$ & $\begin{array}{l}\text { Illustrations, text, distribution maps, photos, videos, and } \\
\text { sounds as well as a search capability. }\end{array}$ \\
\hline & North America Birds & $\begin{array}{l}\text { Peterson Multimedia Guide of almost } 1000 \text { birds with } \\
\text { photographs, videos, bird songs, range maps, and more. For } \\
\text { PC's. }\end{array}$ \\
\hline & $\begin{array}{l}\text { North American Birds } \\
\text { by Sight and Sound }\end{array}$ & $\begin{array}{l}\text { Games and an online manual to help the user learn about } \\
\text { approximately } 700 \text { species of North America birds. For both } \\
\text { PCs and Macs. }\end{array}$ \\
\hline & $\begin{array}{l}\text { National Audubon Society } \\
\text { Interactive CD-Rom Guide }\end{array}$ & $\begin{array}{l}\text { CD-ROM for PCs or Mac covers more than } 700 \text { birds with } \\
2100 \text { photographs, } 700 \text { range maps, bird calls, essays, and }\end{array}$ \\
\hline
\end{tabular}


to North American Birds more.

\begin{tabular}{lll}
\hline Listing software & $\begin{array}{l}\text { North American Bird } \\
\text { Reference Book with } \\
\text { Excalibur 2000 }\end{array}$ & onmymountain.com \\
BirdBase and BirdArea & $\underline{\text { birforwin.html }}$ \\
AviSys & $\underline{\text { Avisys.html }}$ \\
Birder's Diary & $\underline{\text { diary }}$ \\
Flying Emu software & $\underline{\text { Breeding Bird Atlas List }}$ \\
Merlin Species Watcher & Species Watcher Database \\
& MacPeregrine 3.0 & Life lists, custom lists, reports, species accounts. For Macs.
\end{tabular}

Internet sites with field guide information

Northern Michigan Birding

North American Rare Bird Alert

$\underline{\text { Rare Birds }}$

$\underline{\text { Bird Identification Training Center }}$

Patuxent Bird Population Studies

Cornell Laboratory of Ornithology

American Birding Association

$\underline{\text { Online Tips for Birds }}$

Identification of Eastern US Songbirds by Color

The Great Backyard Bird Count Bird Identification Guide

Identification by behavior and location

Nutty Birdwatcher

$\underline{\text { Ducks at a Distance }}$

$\underline{\text { Peterson On Line }}$

$\underline{\text { Surf Birds Advanced Birding Issues }}$

$\underline{\text { Birding Magazine and Kenn Kaufman }}$

Partners in Flight Species Accounts -Table 


\section{APPROACHES TO SPECIES IDENTIFICATION}

\section{The identification problem}

Radford et al. (1976, Chapter 25) list four methods of identification: (1) expert determination, (2) recognition, (3) comparison, and (4) the use of keys and related methods such as synopses, outlines, and tables of characters. Clearly, careful expert determination would by definition be the most reliable method. However, either lack of access to experts or the long wait before experts can furnish identifications makes this approach impractical. It is also tempting to think that we could build expert computer systems to do species identification. Although it is true that that we have a general understanding of the differences between novices and experts (Bransford et al. 1999, Chapter 2), computer scientists are still struggling with how to engineer domain-specific expert systems and their current incarnation in the discipline of knowledge engineering; see, for example, the Institute of Electrical and Electronic Engineers (2002). Pankhurst (1991) devotes a chapter to the discussion of expert systems in species identification, but the approaches seem limited. The current generation of tools, such as Delta and Lucid, are more sophisticated than those described by Pankhurst.

Recognition is based on experience. Morse (1971), cited in Radford et al. (1976), says that this is also a reliable method. However, recognition depends on being self-taught or having learned from some expert and, as stated above, because science is short on taxonomic expertise, this is not an approach that will work for most people. In contrast, comparison covers a broad array of approaches, including searching through museum specimens, reading descriptions, reviewing illustrations, and studying field guide plates. This is the basic approach taken by taxonomists to develop their expertise, but it is time-consuming and requires access to specimens.

Scientifically trained people use keys and related methods successfully, and, for all but the taxa covered by field guides, it is the most widely used approach. Keys offer a step-by-step approach to identifying a species. The classic key is a dichotomous hierarchical tree in which one character is used at each step to make a decision. The user follows a sequential path to the end of the branch, at which time the species of interest is identified. However, keys exist that use more than two choices at each step, multiple paths to reach the correct answer (this is really a directed acyclic graph, not a tree in the strict mathematical sense), and multiple characters at each step. Much has been written about keys and how to construct them (Voss 1952, Radford 1976, Pankhurst 1991). Despite their widespread use in the scientific community (see Fortuner 1989 and Thompson 1999 for some exceptions), keys have some limitations as discussed below, and bad keys abound if the user searchers the archives using the subject category with the phrase "bad key" or "horrible key" in TAXACOM (2001).

\section{Species identification: field guides vs. keys}

Field guides, while available for fewer groups of organisms, are generally recognized as easier to use. Anecdotal evidence, including interviews with half a dozen ornithologists and expert amateur birders, suggests that nobody uses keys to identify birds. Our expert informants did not and did not know of anybody who does. This seems to be due to the high quality of the guides available, the extent of general knowledge even among amateurs, e.g., about life forms and common species, and recurring problems using keys, such as the difficulty in finding the point of error after the user has come to a deadend.

It should be emphasized that, despite their differences (Table 2), keys and field guides often share approaches and elements. For example, some keys contain pictures, and field guides often have an implicit hierarchical tree of two to four levels for identification, e.g., life forms and then groups. Most bird guides have ducks and geese as a life form and dabbling ducks as a group (Peterson 1998, Kaufman 2000). Newcomb's Wildflower Guide (Newcomb1989) has three levels of questions (flower type, plant type, and leaf type) to lead the user to the right section of the book. Petrides's (1998) A Field Guide to Eastern Trees contains broad life forms based on leaf type, and then each section contains a matrix of identification characters. In addition to an excellent series of photographs for each species that allows the user to simply scan for an identification, Uva et al.'s (1997) Weeds of the Northeast contains a typical dichotomous key, as well as 17 shortcut identification tables, seven of which help with specific characters and 10 of which help with specific taxonomic groups.

\section{Species identification: electronic options for keys and guides}

Wilson (1994:1-7), and Edwards and Morse (1995) compare the variety of traditional approaches, i.e., 
field guide techniques and dichotomous and synoptic keys, used to identify organisms and discuss the advantages of interactive keys. Computers can reduce some of the limitations of these approaches and combine some of their strengths. In Chapter 5, Pankhurst (1991) gives an account of the development of ideas about identification using computers. Dallwitz et al. (2000) have provided a list of desirable characteristics for keys, and Dallwitz (2000) has made direct comparisons of features included in existing software packages.

Table 2. Comparisons between taxonomic keys and field guides as identification tools. New software will be able to combine both approaches in one tool.

\begin{tabular}{|c|c|c|}
\hline \multirow[b]{2}{*}{ Characteristic } & \multicolumn{2}{|c|}{ Approach used by } \\
\hline & Systematic keys & Field guides \\
\hline Identification strategy & Process of elimination & Comparison \\
\hline Basis of identification & Matrix of characters & Pictures and field marks \\
\hline Starting level of key & Many taxonomic levels & Life form \\
\hline Implicit key type & Narrow and deep & Broad and shallow \\
\hline Number of levels in key & $5-50 ?$ & $1-6 ?$ \\
\hline Location of use & Usually in the lab & Field \\
\hline Context & Only the specimen & Specimen, location, habitat, season \\
\hline Specimen & Often dead & Living \\
\hline Use & Strictly identification & Identification and basic information \\
\hline Author & Usually scientific expert & Naturalist \\
\hline Coverage & Taxonomic & Taxonomic, regional, and life form \\
\hline Audience & Normally skilled biologist & Public \\
\hline Language style & Technical & Limited technical usage \\
\hline Species covered & All taxa & Major groups of large organisms \\
\hline Arrangement of material & Hierarchical key with descriptions & Book format with pictures \\
\hline Key type & Mostly dichotomous & Variable, not always present \\
\hline Search mode & N/A & Scan \\
\hline Field portable & Yes & Yes \\
\hline
\end{tabular}


Table 3. Comparisons between taxonomic keys and field guides as identification tools. New software will be able to combine both approaches in one tool.

\begin{tabular}{|l|l|l||}
\hline Characteristics & Systematic keys & Field guides \\
\hline Identification strategy & process of elimination & Comparison \\
\hline Basis of identification & matrix of characters & pictures and field marks \\
\hline Starting level of key & many taxonomic levels & life form \\
\hline Implicit key type & narrow and deep & broad and shallow \\
\hline Number of levels in key & $5-50 ?$ & $1-6 ?$ \\
\hline Location of Use & usually in the lab & field \\
\hline Context & only the specimen & specimen, location, habitat, season \\
\hline Specimen & often dead & living \\
\hline Use & strictly identification & identification + basic information \\
\hline Author & usually scientific expert & naturalist \\
\hline Coverage & taxonomic & Taxonomic, regional and life form \\
\hline Audience & normally skilled biologist & public \\
\hline Language style & technical & limited technical usage \\
\hline Species covered & all taxa & major groups of large organisms \\
\hline Arrangement of material & hierarchical key with descriptions & book format with pictures \\
\hline Key type & mostly dichotomous & Variable, not always present \\
\hline Search mode & NA & scan \\
\hline Field portable & yes & yes \\
\hline
\end{tabular}

Despite these useful developments beyond traditional keys, we believe that some essential issues of identification have not been addressed, especially in light of what we know about how people use field guides. Given that identification is often an unconscious process, software tools should try to mimic the way we identify objects naturally and help reduce the user's frustration when the process becomes more explicit. We suggest that software should: (1) provide training tools and games to let people become familiar with the "cast of characters" slowly, instead of being overwhelmed and confused by having to learn a lot of new things at once; (2) work to reduce the time necessary to identify a species by choosing likely possibilities from a line-up approach; and (3) suggest further queries that will aid in making the final positive identification. For the first point, computer games can be used to introduce and quiz users. For the second point, computer programs can use basic data about the observation, such as time, location, and habitat, and specimen characteristics such as size, color, etc., to form the line-up. This process is similar to the one suggested by Wilson (1994:37) and would bypass the traditional key approach. This approach may not be possible or as desirable as using a very simple key.

One example of a simple key is the computer-based guide shown for orchids on page 123 of Pankhurst (1991). This key emphasizes flower shape. The best example of a user-friendly key we have found on the Internet is An interactive key to the Katydids of La Selva, Costa Rica (Orthoptera: Tettigoniidae) by Piotr Naskrecki. He presents a visual key for 60 species with simple point-and-click choices. Three levels in the identification tree are needed to reach a final choice. Naskrecki was able to take this approach because the number of species at La Selva is relatively small (about 65). He lists similar species at the end of his branches to help users make a positive identification. 


\section{FUTURE OF ELECTRONIC FIELD GUIDES: DESIGN AND USE}

Because they incorporate contemporary software userinterface techniques such as "progressive disclosure," i.e., the hiding of information and user interface choices until the task at hand demands their use (Mandel 1997:40), and Web linking, electronic field guides hold the promise of being able to tailor their presentations to the expertise of the user and to conveniently present access to species that may be confused with the proposed identification. These issues were recognized more than a century ago by Grant (1895:4), who advised the novice field guide user to "Begin with ... the most abundant and most easily recognized [birds and focus on those] with striking marks either of song or plumage to serve as a sign for certain identification." In this section, we discuss a number of principles and practices aimed at realizing this promise. Some are already in use in our own and other efforts. Others we believe will be important in the future.

\section{Software design}

In general, electronic publishing will continue to break down traditional publishing limitations. The increasing adoption of Internet publishing should facilitate collaborative efforts between computer scientists and biologists to build Electronic Field Guides (EFGs) that are highly specific in their subject matter and are not constrained in either the amount of information or the number of quality photographs they contain. Objectoriented technologies, especially the Java programming language and the Extensible Markup Language (XML) standardized by the World Wide Web Consortium (2002), support extensible software systems. Their generality will allow people to produce, as special cases, EFGs and related tools that have a very specific taxonomic focus or geographical coverage; large clear, photographs; and the ability to compare similar species side by side dynamically. The information displayed will depend on the seasonal occurrence of each life stage and on the skill, experience, and age of the user. Better identification tools will provide options for multiple life stages and traits, e.g., adults, juveniles, sound recordings, feathers, nests for birds, to identify the same set of species. Programs will include built-in learning tools, ecological relationships among species, and occurrences observed by the user or the user community, as in the "citizen science" approach described below.

\section{Hardware use and developments}

New digital cameras, flat-bed scanners, and slider scanners make the collection of images very inexpensive. Furthermore, image-processing software and software tools for building Web sites permit individuals to publish their own electronic guides with only a small capital investment. However, taking this information to the field in electronic form with highresolution color displays requires expensive equipment that is not yet available in consumer models. As a substitute, scientists and field naturalists are making their own miniguides by laminating plates of images created with ink jet printers on glossy paper. These custom-made pocket guides can be very helpful and meet the objectives of an easy-to-use, high-quality local guide (see Foster 1999).

The most important advance in the near future will probably stem from the ability of Personal Digital Assistants (PDAs) to store and display many highquality images. At that point, paper field guides will start to be replaced by digital equipment. The marriage of video cameras, PDAs, and Global Positioning System technologies will go a long way toward producing a tool that can be used to identify specimens in the field and collect electronic vouchers. On the data collection side, the CyberTracker and the somewhat dormant Mobile Computing in a Fieldwork Environment projects originally at the University of Kent show how much information can already be gathered in the field using a Palm Pilot. In our laboratory we are developing software to connect PDAs to the electronic field guides our software generates. Bryan Heidorn has coined the term "TeleBotany" to describe his working system of PDAs and laptops in the field; the system is connected to experts by wireless and mobile telephone links. Rapidly decreasing hardware costs will make such use of handheld computing equipment routine in the future.

\section{Testing identification tools}

The software development adage "If it isn't tested, it doesn't work" also applies to field guides. A crucial component of electronic guides is the identification component. We maintained above that field guides are good tools for species identification by the public and supported our view with a variety of arguments. Furthermore, electronic versions offer more flexibility than paper guides. Nonetheless, there has been little scientific study of how successfully field guides, 
whether paper or electronic, serve as learning and identification tools. Two reports on the Internet that measured people's ability to identify species correctly (Montagne and Bergen 1996, Gordon 1999, Haas 1999) suggest that results vary widely. Clearly, a more concerted effort is needed to understand the issues, processes, and needs of user communities and to design test regimes that take these factors into account.

\section{Learning theory and knowledge representation}

A neglected approach to designing field guides and keys is to build on what is known about how the human mind works. Psychologists, anthropologists, neurobiologists, educators, and computer scientists are rapidly advancing our understanding of how humans learn. Elementary cognitive science (Matlin 1994), the study of folk taxonomies (Berlin et al. 1973, 1974, Berlin 1992, Atran 1998) and taxonomic representations by children and nonexpert adults (Carey 1985, Carey and Gelman 1991, Tunnicliffe 1996, 1999, Myers 1998, Reiss and Tunnicliffe 1999) suggest some useful perspectives about the design of field guides. Information should be arranged in a hierarchical way, and, although the number of levels should not be deep (three or four), they can be broad at the species level. After the kingdom level, adults use life form as the next level to distinguish the groups in the hierarchy. Appropriate characters include size, color, and unusual features, which is entirely consistent with the 1895 recommendations of Grant cited earlier.

\section{APPLICATION OF ELECTRONIC FIELD GUIDES: CITIZEN SCIENCE}

\section{The birding model}

Dr. Rick Bonney at Cornell's Laboratory of Ornithology coined the term "citizen science" in the 1990s during the laboratory's efforts to engage the public in bird-population monitoring projects. Currently, the laboratory has a large number of such projects that it has initiated or hosts in partnership with other groups.

A public knowledgeable in bird identification has made it possible for tens of thousands of people to get involved in bird censuses such as the Christmas Bird Count, the Breeding Bird Survey, and FeederWatch. The ability to identify birds reliably is the singular skill that has allowed public participation in these environmental monitoring and research projects. The scientific community has greatly benefited from public participation (for example, Hochachka and Dhondt 2000). Without this legion of volunteers, scientists would not be able to gather data over the time periods and geographic regions now possible. Such data gathered over extended temporal and spatial scales are extremely valuable for monitoring the environment.

Because of the great public popularity of birding, public expertise is being put to use for scientific studies. People are enthusiastic about participating because it gives more purpose to their efforts, and they learn about the process of science. Scientists are enthusiastic about the projects because they can answer questions that would be impossible to approach without a network of volunteers.

These same characteristics of citizen scientist partnerships are evident in a number of other programs such as MusselWatch, the Fourth of July Butterfly Count, and Discover Life. Other programs at the USGS Patuxent Wildlife Research Center and the Texas Nature Tracker's Office have government sponsorship.

\section{Extensions of the citizen science paradigm}

Two obvious ways to extend the citizen science paradigm are under way. We focus our attention on North American projects, although there are exciting citizen science efforts in other parts of the world that are not discussed here.

The first is for scientists to team up with students, as is happening with the Monarch Watch project, the Journey North, the Illinois UrbanWatch, the NatureWatch, and the Globe Program (see the Student and Scientist Partnerships Conference for a discussion of these initiatives). In the usual citizen science approach, rules and regulations are disseminated by a central group of scientists who might work with educators to present the rationale and procedure in layman's terms. The observers enjoy the activity but are not often involved in the analysis or interpretation of the data.

The second extension is to allow people to submit data about a topic or theme without a specific protocol designed by scientists. The North American Butterfly Association's Sightings page and the Hudson River Almanac are examples of this approach. Here, in this bottom-up approach, the rules for participation were 
not defined by a scientific group but, rather, grew out of the interest of the participants. It is also worth noting that, on occasion, methodologies have been proposed by volunteer/school monitoring projects such as Lichens that were subsequently adopted as part of the Canada Nature Foundation's NatureWatch in partnership with Environment Canada.

For biodiversity studies, citizen science partnerships could include data about location, the number of individuals of a species, specific individuals, life stage, condition, behavior, and ecological interactions. Ecological data of this type can be used to address many kinds of broader ecological questions, including population trends, species distributions, phenology, and the structure of food webs. This public interest focus could also be applied if it addressed such issues as the distribution of invasive species or the phenology of plants for global warming.

A largely ignored component of publicly gathered biodiversity data is the specification of the quality of data and metadata. Several approaches are possible, ranging from just filtering missing data to using quality assurance plans (Resources Information Standards Committee 2000).

\section{FINAL COMMENTS}

Field guides are a way for people to connect with the environment by putting a specific face on the term "biodiversity." The ecoinformatics revolution should help biologists take advantage of the rapid advances in digital technologies to share their knowledge about biodiversity with nonspecialists. The nonspecialists, in turn, through citizen science projects, are showing that their knowledge of species can be used to help monitor ecological changes as they relate to evolutionary dynamics and more pressing issues such as biodiversity loss, invasive species, and global climate change (Luchencho et al. 1991).

Responses to this article can be read online at: http://www.consecol.org/vol7/issl/art3/responses/index.html

\section{Acknowledgments:}

Jennifer Forman, Susan Abruzzi, Melissa Doyle, and Kate Van Dine provided helpful comments on drafts of this paper. We thank the anonymous reviewers for their thoughtful suggestions.

\section{APPENDIX 1}

The following file contains a selection of site data from a range of global environments. The entire contents can only be read using VegClass software, although certain sections can be opened in Microsoft Access.

Field Guide to Common Western Grasshoppers

Wildflower Field Guide

USGS site Wyoming Rare Plant Field Guide

Field Guide to the Psilocybin Mushroom Species common to North America

A Field Guide For Your School Yard

Field Guide To The San Gabriel Mountains: Natural History

Field Guide to Noxious and Other Selected Weeds of British Columbia

Underwater Field Guide to Ross Island \& McMurdo Sound, Antarctica

Field guide to Irish fairies

Plant Field Guide: Visual Guide

Field Guide to the Praire

BioImages: The Virtual Field-Guide (UK) Poaceae (grasses)

Indiana Dunes

A field guide to economically important seaweeds of northern New England

Field Guide To Anemone Fishes And Their Host Sea Anemones

Field Guide to Some North American Seals or Sea Lion

On-line field guide to the diagnosis and management of potato late blight

Field Guide To The Psilocybin Mushroom

A Field Guide for Ground Checking Southern Pine Beetle Spots

Aquatic Invertebrates Illustrated Field Guide

Salmon

An Online Guide for Amphibians in the United States and Canada 
Reef check

World Billfish Series Species Identification

Timber Harvest

Meat Species Identification

Species identification of intestinal microsporidiosis in HIV-positive patients using the polymerase chain reaction

An ACQUIRE @ expert system application for whale identification

Search the Seafood List

Mollusks Species Identification Keys

Fish Identification

Turtle Identification

Bird feather for airplane bird interactions

Nature mappers

Globe program

Chestnut Identification

Forestry scaling manual

Identification of Grasses

Identification of Neisseria and related species

Salmon and Other fish

Midwestern Wetland FloraField Office Guide to Plant Species List and Identification Key

Diagnostic Standards and Classification of Tuberculosis

The making of FishBase

Methodology For Volunteer/School Monitoring :Projects Using Lichens

Growing Fusarium Species for Identification

Commercially important fish

Identification And Comparison Of Varroa Species Infesting Honey Bees

Butterfly Species Identification Guide

Parrotlet Species Identification

Endangered species identification

Corn and soy field guide

Western Wetland Flora Field Office Guide to Plant Species

A Field Guide To Aquatic Exotic Plants And Animals", 1995.

Forests and timber: a field guide to exotic pests and diseases

Macrofungi of Costa Rica

Field Guide to Freshwater Invertebrates

World of Dermatophytes: A Pictorial Laboratory Identification

UL Butterfly guide for Europe

A quick guide to Pythons

\section{LITERATURE CITED}

American Ornithologists' Union. 2000. Forty-second supplement to the American Ornithologists' Union checklist of North American birds. The Auk 117:847-858.

Arlen, R. 1999. Reviews of frog call recordings. Available online at http://coloherp.org/frogcalls.html.

Atran, S. 1998. Folk biology and the anthropology of science: cognitive universals and cultural particulars. Behavioral and Brain Sciences 21:547-609.

Bailey, F. M. 1889. Birds through an opera glass. Houghton, Mifflin, New York, New York, USA.

Balmford, A., A. Bruner, P. Cooper, R. Costanza, S. Farber, R. E. Green, M. Jenkins, P. Jefferiss, V. Jessamy, J. Madden, K. Munro, N. Myers, S. Naeem, J. Paavola, M. Rayment, S. Rosendo, J. Roughgarden, K.
Trumper, and R. Kerry Turner. 2002. Economic reasons for conserving wild nature. Science 297:950-953.

Berlin, B. 1992. Ethnobiological classification. Princeton University Press, Princeton, New Jersey, USA.

Berlin, B., D. Breedlove, and P. Raven. 1973. General principles of classification and nomenclature in folk biology. American Anthropologist 74:214-242.

Berlin, B., Breedlove, D., and P. Raven. 1974. Principles of Tzeltal plant classification. Academic Press, New York, New York, USA.

Blackmore, S. 1996. Knowing the Earth's biodiversity: challenges for the infrastructure of systematic biology. Science 274: 63-64.

Bisby, F. A. 2000. The quiet revolution: biodiversity informatics and the Internet. Science 289:2309-2312. 
Bransford, J. D., A. L. Brown, and R. R. Cocking, editors. 1999. How people learn: brain, mind, experience, and school. National Academies Press, Washington, D.C., USA.

Carey, S. 1985. Conceptual change in childhood. MIT Press Series in Learning, Development, and Conceptual Change. MIT Press, Cambridge, Massachusetts, USA.

Carey, S., and R. Gelman, editors. 1991. The epigenesis of mind: essays on biology and cognition. Jean Piaget Symposium Series. Lawrence Erlbaum Associates, Hillsdale, New Jersey, USA.

Cassie, B., J. Glassberg, A. Swengel, and G. Tudor. 2001. North American Butterfly Association (NABA) checklist and English names of North American butterflies. Second edition. North American Butterfuly Association, Morristown, New Jersey, USA.

Commission of the European Communities. 1998. Developing deep-water fisheries: data for their assessment and for understanding their interaction with and impact on a fragile environment. Available online at http://www.sams.ac.uk/dml/projects/dwf/development.html \#3.

Cordell H. K., N. G. Herbert, and F. Pandolfi. 1999. The growing popularity of birding in the United States. Birding 31:168-176.

Cordell, H. K., B. L. McDonald, J. A. Briggs, R. J. Teasley, R. Biesterfeldt, J. Bergstrom, and S. H. Mou. 1998. Emerging markets for outdoor recreation in the United States: a report to the Sporting Goods Manufacturing Association and the Outdoor Products Council. Available online at http://www.srs.fs.fed.us/trends/sgma.html.

Dallwitz, M. J. 2000. A comparison of interactive identification programs. Available online at http://biodiversity.uno.edu/delta/www/comparison.htm.

Dallwitz, M. J., T. A. Paine and E. J. Zurcher. 2000. Principles of interactive keys. Available online at http://www.biodiversity.uno.edu/delta/www/interactivekeys. $\underline{\mathrm{htm}}$.

Daily, G. C., editor. 1997. Nature's services: societal dependence on natural ecosystems. Island Press, Washington, D.C., USA.

Day, M. 1998. Metadata and biodiversity information: a report from a US symposium on metadiversity. Available online at http://www.ariadne.ac.uk/issue18/Metadiversity.

Edwards, M. and D. R. Morse. 1995. The potential for computer-aided identification in biodiversity research. Trends in Ecology and Evolution 10:153-158.

Edwards, J. L., M. A. Lane, and E. S. Nielsen. 2000. Interoperability of biodiversity databases: biodiversity information on every desktop. Science 289: 2312-2314.
Fortuner, R.1989. A new description of the process of identification of plant parasitic nematode genera. Pages 3544 in R. Fortuner, editor. Nematode identification and expert system technology. Plenum, New York, New York, USA. Also available online at http://www.math.ucdavis.edu/ milton/genisys/descproc.htm 1.

Foster, R. 1999. Rapid color guides. Chicago Field Museum, Chicago, Illinois, USA. Also available online at http://www.fmnh.org/research_collections/ecp/ecp_sites/rrc _plant_web/plant_web/default.htm.

Gewin, V. 2002. All living things, online. Nature 418:362363.

Godfray, H. C. J. 2002. Challenges for taxonomy. Nature 417:17-19.

Gordon, J. D. M., editor. 1999. Developing deep-water fisheries: data for their assessment and for understanding their interaction with and impact on a fragile environment. Final consolidated report of the Commission of the European Communities Shared Cost DGXIV FAIR PROJECT CT 950655 1996-1998. Available online at http://www.sams.ac.uk/dml/projects/dwf/development.html $\# 3$.

Grant, J. B. 1895. Our common birds and how to know them. Fifth edition. Scribner's, New York, New York, USA.

Haas, G. 1999. Fish species identification and collection errors, problems and consequences: the unrecognized skills and lost value of taxonomy. Available online at http://www.tucanada.org/bulltrout2/abstracts_html/haas_4_t axonomy.htm.

Hill, N. 1965. The birds of Cape Cod. William Monroe, New York, New York, USA.

Hochachka, W. M., and A. A. Dhondt. 2000. Densitydependent decline of host abundance resulting from a new infectious disease. Proceedings of the National Academy of Science 97: 5303-5306. Also available online at http://www.pnas.org/cgi/content/full/97/10/5303.

Institute of Electrical and Electronics Engineers. 2002. IEEE intelligent systems. IEEE Computer Society, Los Alamos, California, USA.

Janzen, D., W. Hallwachs, J. Jimenez, and R. Gamez. 1993. The role of parataxonomists, inventory managers, and taxonomists in Costa Rica's National Biodiversity Inventory. Pages 223-254 in Word Resources Institute, National Biodiversity Institute of Costa Rica, Rainforest Alliance, and African Centre for Technology Studies. Biodiversity prospecting: using genetic resources for sustainable development. World Resources Institute, Washington, D.C., USA.

Kaufman, K. 2000. Focus guide to the birds of North 
America. Houghton Mifflin, Boston, Massachusetts, USA.

Kartesz, J. T., and J. W. Thieret. 1991. Common names for vascular plants: guidelines for use and application. Sida 14:421-434.

Knapp, S. 2000. What's in a name? Nature 408:33.

Leahy, C. 1982. The birdwatcher's companion: an encyclopedic handbook of North American birdlife. Hill and Wang, New York, New York, USA.

Livo, L. J. 1998. Field guides of the United States (by state). Available online at http://coloherp.org/fldguide/fgusa.html.

Lubchenco, J., A. M.Olson, L. B. Brubaker, S. R. Carpenter, M. M. Holland, S. P. Hubbell, S. A. Levin, J. A. Macmahon, P. A. Matson, J. M. Melillo, H. A. Mooney, C. H. Peterson, H. R. Pulliam, L. A. Real, P. J. Regal, and P. G. Risser. 1991. The sustainable biosphere initiative: an ecological research agenda. Ecology 72:371412. Also available online at http://esa.sdsc.edu/91annualrep.htm.

Mandell, T. 1997. Elements of user interface design. John Wiley, New York, New York, USA.

Matlin, M. W. 1994. Cognition. Third edition. Harcourt Brace, New York, New York, USA.

McAllister, D. 1997. The term "biodiversity." Available online at http://www.biodiversity.uno.edu/ gophtax/_gophtax.97/175 $\underline{7 . h t m l}$.

Montagne, D. E., and M. Bergen. 1996. Quality control and assessment of infaunal identification and enumeration: the SCBPP experience. Available online at http://www.sccwrp.org/pubs/annrpt/96/ar-17.htm.

Morse, L. E. 1971. Specimen identification and key construction with time-sharing computers. Taxon 29:269282.

Myers, G. 1998. Children and animals: social development and our connections to other species. Westview Press, Boulder, Colorado, USA.

Newcomb, L. 1989. Newcomb's wildflower guide. Little Brown, New York, New York, USA.

Pankhurst, R. J. 1991. Practical taxonomic computing. Cambridge University Press, Cambridge, UK.

Parkes, K. C. 1978. A guide to forming and capitalizing compound names of birds in English. Auk 95:324-326.

Pennisi, E. 2000. Taxonomic revival. Science 289:23062308.

Peterson, R. T. 1998. A field guide to the birds. First edition. Houghton Mifflin, Boston, Massachusetts, USA.

Peterson, R. T. 1998. A field guide to the birds: a completely new guide to all the birds of eastern and central North America. Fourth edition. Houghton Mifflin, Boston, Massachusetts, USA.

Petrides, G. A. 1998. A field guide to eastern trees. Houghton Mifflin, Boston, Massachusetts, USA.

President's Council of Advisors on Science and Technology. 1998. Teaming with life: investing in science to understand and use living capital. Available online at http://www.ostp.gov/Environment/html/teamingcover.html.

Radford, A. E., W. C. Dickison, J. R., Massey, and C. R. Bell. 1976. Plant identification. Chapter 25 in A. E. Radford, W. C. Dickison, J. R. Massey, and C. R. Bell. Vascular plant systematics. Harper and Row, New York, New York, USA. Also available online at http://www.ibiblio.org/unc-

biology/herbarium/courses/CHPT25.html.

Raven, P., and E. O. Wilson. 1992. A fifty-year plan for biodiversity surveys. Science 258:1099-1100.

Read, G. 1997. The term "biodiversity." Available online at http://www.biodiversity.uno.edu/ gophtax/_gophtax.97/176 $\underline{0 . h t m l}$.

Reid, W. V., and K. R. Miller. 1989. Keeping options alive: the scientific basis for conserving biodiversity. World Resources Institute, Washington, D.C., USA.

Reiss, M. J., and S. D. Tunnicliffe. 1999. Building a model of the environment: how do children see plants? Available online

http://www2.educ.sfu.ca/narstsite/conference/reisstunnicliff e/reisstunnicliffe.html.

Resources Information Standards Committee, British Columbia Ministry of Sustainable Resources Management. 2000. Rennaissance (1:20 000): fish and fish habitat inventory: quality assurance procedures. Version 1. Available online at http://srmwww.gov.bc.ca/risc/pubs/aquatic/quality/">.

Ricketts, T. H., E. Dinerstein, D. M. Olson, and C. J. Loucks. 1999. Terrestrial ecoregions of North America: a conservation assessment. Island Press, Washington, D.C., USA.

Royal Ontario Museum. 1999. Build your own field guide. Available online at http://romlx6.rom.on.ca/ontario/fieldguides.html.

Rumble, J. 1999. Standards for scientific and technical data. Available online at http://www.tdwg.org/standardstdwg.htm.

Sibley D. A. 2000. The Sibley guide to birds. Random House, New York, New York, USA. 
Stein, B. A., L. S. Kutner, and J. S. Adams, editors. 2000. Precious heritage: the status of biodiversity in the United States. Oxford University Press, Oxford, UK.

TAXACOM 2001: Biological Systematics and Biocollections Computerization Discussion List http://www.usobi.org/archives/taxacom.html.

Thompson, F. C., editor. 1999. Fruit fly expert identification system and systematic information database: a resource for identification and information on fruit flies and maggots, with information on their classification, distribution and documentation. Backhuys, Leiden, The Netherlands.

Tunnicliffe, S. D. 1996. Conversations within primary school parties visiting animal specimens in a museum and zoo. Journal of Biological Education 30:130-141.

Tunnicliffe, S. D. 1999. Using the zoo as a science education resource. Available online at http://www.zoonews.ws/IZN/294/IZN-294.html\#sdt.

Uva, R. H., J. C. Neal, and J. M. Ditomaso. 1997. Weeds of the northeast. Cornell University Press, Ithaca, New York, USA.

Voss, E. G. 1952. The history of keys and phylogenetic trees in systematic biology. Journal of the Scientific Laboratories of Denison University 43:1-25.

World Wide Web Consortium. 2002. Extensible markup language $(X M L)$ Available online at http://www.w3.org/XML.

Wilson, E O. 2000. A global biodiversity map. Science 289: 2279 .

Wilson, E. O., and F. M. Peter, editors. 1998. Biodiversity. National Academies Press, Washington, D.C., USA.

Wilson, N. 1994. Identifying organisms with computers: an implementation of a computerized synoptic identification system with fungi as a test case. Thesis. University of California, Santa Cruz, California, USA. Available online at http://collectivesource.com/taxy/thesis.html.

Youth, H. 1999. The best in the field. ZooGoer 28. Available online at http://www.fonz.org/zoogoer/zg1999/28(4)fieldguides.htm.

Ytow, N., D. R. Morse, and D. M. Roberts. 2001. Nomencurator: a nomenclatural history model to handle multiple taxonomic views. Biological Journal of the Linnean Society 73:81-86. 